\title{
Influence of methyl group in a quinoline moiety on optical and light-induced properties of side-chain azo-polymers
}

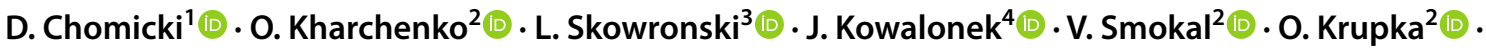 \\ B. Derkowska-Zielinska ${ }^{1}$ (D)
}

Received: 18 December 2020 / Accepted: 24 February 2021 / Published online: 13 March 2021

(c) The Author(s) 2021

\begin{abstract}
We present the optical and photochromic properties as well as surface quality of thin films of the methacrylic copolymers containing 2-methylquinoline and quinoline azo-dyes in side chain. The extinction coefficient and refractive index were determined using spectroscopic ellipsometry combined with transmittance measurements. Photo-responsive behavior was investigated by determination of trans-cis photoisomerization rates under irradiation with unpolarized $365 \mathrm{~nm}$ light. We found that optical properties as well as photoisomerization rates of investigated polymers are dependent on the presence of a methyl substituent in the 2 nd position of the quinoline moiety. The quality of the thin films was examined using Atomic Force Microscopy measurements.
\end{abstract}

Keywords Quinoline azo-dye polymers · Optical properties $\cdot$ Extinction coefficient $\cdot$ Refractive index $\cdot$ AFM Photoisomerization

\section{Introduction}

Azobenzene is a molecule consisting of two phenyl rings linked by an azo (-N=N-) bridge forming an extensive conjugated $\pi$-electron system (Sekkat and Knoll 2002; Bandara and Burdette 2012; Wang 2017). Its derivatives are extensively studied because of their spectroscopic, photochromic, nonlinear optical properties and photostability (Sekkat and Knoll 2002; Bandara and Burdette 2012; Wang 2017; Natansohn and Rochon 2002). These properties make azobenzenes

D. Chomicki

chomicki@doktorant.umk.pl

$\triangle$ B. Derkowska-Zielinska beata@fizyka.umk.pl

1 Institute of Physics, Faculty of Physics, Astronomy and Informatics, Nicolaus Copernicus University in Torun, Grudziadzka 5/7, 87-100 Torun, Poland

2 Faculty of Chemistry, Taras Shevchenko National University of Kyiv, 64/13 Volodymyrska St., Kyiv 01601, Ukraine

3 Institute of Mathematics and Physics, UTP University of Science and Technology, S. Kaliskiego 7, 85-796 Bydgoszcz, Poland

4 Faculty of Chemistry, Nicolaus Copernicus University in Torun, Gagarina 7, 87-100 Torun, Poland attractive candidates for applications, such as optical switches, optical limiters, optical data storage, nonlinear optical devices, and holography (Sekkat and Knoll 2002; Bandara and Burdette 2012; Natansohn and Rochon 2002; Halabieh et al. 2004; Ho et al. 1995; Kawata and Kawata 2000; Xie et al. 1994; Zidan and Ajji 2011; DerkowskaZielinska et al. 2016, 2017a). Azobenzene can exist in two isomeric forms (stable trans and metastable cis) and reversible trans-cis isomerization is one of its key features (Sekkat and Knoll 2002; Bandara and Burdette 2012; DerkowskaZielinska et al. 2017a). Trans-cis isomerization can be induced by irradiation of the appropriate wavelength, while cis-trans reaction can also occur spontaneously in the dark. Changing the conformation of azobenzene molecule causes the weakening of the intense $\pi-\pi^{*}$ absorption band (centered around $320 \mathrm{~nm}$ ) and the strengthening of the weak $n-\pi^{*}$ band (around $440 \mathrm{~nm}$ ) (Sekkat and Knoll 2002; Bandara and Burdette 2012; Wang 2017; Merino and Ribagorda 2012).

Properties of azobenzene derivatives, such as absorption maximum position, refractive index, optical energy gap, isomerization rates, thermal stability, bond lengths, and dipole moment, can be tailored by introducing various substituents into the phenyl ring or substituting whole rings with heterocyclic moieties (Sekkat and Knoll 2002; Bandara and Burdette 2012; Halabieh et al. 2004; Tawa et al. 2000;

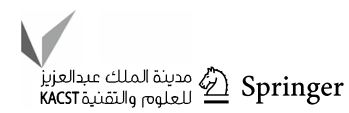


Derkowska-Zielinska et al. 2017b, 2018, 2019; Chomicki et al. 2020; Zeyada et al. 2013; El-Ghamaz et al. 2013). Understanding the factors that affect each of these properties is important in designing novel materials suitable for specific applications.

Quinoline azobenzene derivatives are interesting for their optical, thermal and electrical properties. Recently, some of physicochemical properties of azo-quinoline derivatives have been studied (Zeyada et al. 2013; El-Ghamaz et al. 2013, 2014, 2015; Arslan et al. 2017; Sankar et al. 2007; Sarkar et al. 2014; Ghanadzadeh et al. 2012; Saylam et al. 2014; Yan et al. 2013; Szala et al. 2017), but knowledge of these compounds and their light-induced behavior remains low. Finding systems showing attractive optical response is very important for their practical use in photonics and optoelectronics.

To form thin films, azo-chromophores may be incorporated into polymer matrices (as guest-host systems) or by covalent bonding into polymer main- or side chain. Functionalized systems allow higher dye loading levels by preventing phase separation or microcrystallization and they enhance thermal and temporal stability. The advantage of side-chain arrangement over main-chain is chromophore content, available functionality, increased stability as well as ease of preparation and processing (Halabieh et al. 2004; Tirellia et al. 2000).

In this study, we present optical and photochromic properties of thin films of new methacrylic copolymers possessing 2-methyl-5-phenylazoquinoline and 5-phenylazoquinoline chromophores in side chain. It should be mentioned that this work is a continuation of our previous research (Chomicki et al. 2020). However, we focus on the influence of methyl substituent in the 2 nd position of the quinoline moiety on surface quality of the film using Atomic Force Microscopy (AFM), and on optical constants (i.e., extinction coefficient and refractive index) determined by spectroscopic ellipsometry (SE) together with transmittance measurements. We investigated the photoisomerization behavior of all the side-chain quinoline azo-dye polymers upon irradiation with unpolarized $365 \mathrm{~nm}$ light and determined the trans-cis isomerization rate.

\section{Experimental studies}

\section{Materials and synthesis}

Methacryloyl chloride 97\% (Sigma-Aldrich) was vacuumdistilled, immediately before use. Methyl methacrylate (MMA) 99\% (Sigma-Aldrich) was washed with aq $\mathrm{NaOH}$ to remove inhibitors, dried with $\mathrm{CaCl}_{2}$, under nitrogen at reduced pressure. Quinolin-8-ol (1) 99\%, 2-methylquinolin8-ol (2) 98\%, aniline (a) 99.5\%, 4-methoxyaniline (b) 99\%,
N,N-dimethylformamide anhydrous, 99.8\%, were purchased from Sigma-Aldrich and used without further purification.

The 5-azo-8-hydroxyquinoline dyes (compounds 1a, $2 \mathrm{~b}, 2 \mathrm{~d}$ ) were prepared by coupling the diazonium salt of aromatic amine correspondingly with quinolin-8-ol (1) or 2-methylquinolin-8-ol (2), according to the procedure published previously (Chomicki et al. 2020).

5-[(E)-phenyldiazenyl]quinolin-8-ol (1a). Yield $90 \%$. $\mathrm{Mp}=174-177^{\circ} \mathrm{C} .{ }^{1} \mathrm{H}$ NMR $\left(\right.$ DMSO-d $\left._{6} ; 500 \mathrm{MHz}\right) \delta, \mathrm{ppm}$ : $7.11(\mathrm{~d}, 1 \mathrm{H}, \operatorname{ArH}), 7.48(\mathrm{~d}, 1 \mathrm{H}, \operatorname{ArH}), 7.57$ (d, 2H, ArH), 7.70 (t, 1H, ArH), 7.93 (d, 2H, ArH), 8.00 (d, 1H, ArH), 8.91 $(\mathrm{d}, 1 \mathrm{H}, \mathrm{ArH}), 9.26(\mathrm{~d}, 1 \mathrm{H}, \mathrm{ArH})$.

2-methyl-5-[(E)-p-phenyldiazenyl]quinolin-8-ol (2a). Yield $90 \% . \mathrm{Mp}=197^{\circ} \mathrm{C} .{ }^{1} \mathrm{H}$ NMR (DMSO-d $\left.\mathrm{d}_{6} ; 400 \mathrm{MHz}\right) \delta$, ppm: $2.60\left(\mathrm{~s}, 3 \mathrm{H}, \mathrm{CH}_{3}\right), 6.42(\mathrm{~d}, 1 \mathrm{H}, \mathrm{ArH}), 7.21(\mathrm{t}, 1 \mathrm{H}, \mathrm{ArH}), 7.32$ (d, 1H, ArH), $7.42(\mathrm{~d}, 2 \mathrm{H}, \mathrm{ArH}), 7.72(\mathrm{~d}, 2 \mathrm{H}, \mathrm{ArH}), 7.95(\mathrm{~d}$, $1 \mathrm{H}, \mathrm{ArH}), 9.03(\mathrm{~d}, 1 \mathrm{H}, \mathrm{ArH})$.

5-[(E)-(4-methoxyphenyl)diazenyl]-2-methylquinolin-8-ol (2b). Yield 98\%. Mp $=193-195^{\circ} \mathrm{C} .{ }^{1} \mathrm{H}$ NMR (DMSO-d $\mathrm{d}_{6}$; $400 \mathrm{MHz}) \delta$, ppm: 2.60 (s, 3H, $\left.\mathrm{CH}_{3}\right), 3.82\left(\mathrm{~s}, 3 \mathrm{H}, \mathrm{OCH}_{3}\right)$, $6.36(\mathrm{~d}, 1 \mathrm{H}, \operatorname{ArH}), 6.97$ (d, 2H, ArH), 7.29 (d, 1H, ArH), 7.67 (d, 2H, ArH), 7.88 (d, 1H, ArH), 9.00 (d, 1H, ArH).

\section{Synthesis of 8-methacryloxyquinoline azo dyes}

Methacrylic azomonomers m1a, m2a, $\mathrm{m} 2 \mathrm{~b}$ were obtained by adapting procedure described for the styryquinoline-containing methacrylates (Smokal et al. 2018). Methacryloyl chloride is reacted with the suitable hydroxy derivative of azoquinoline dyes $1 \mathrm{a}, 2 \mathrm{~b}, 2 \mathrm{~d}$ in the presence of triethylamine.

5-[(E)-phenyldiazenyl]quinolin-8-yl 2-methylprop-2-enoate (m1a). Orange powder, yield $51 \% . \mathrm{Mp}=128-129^{\circ} \mathrm{C} .{ }^{1} \mathrm{H}$ NMR (DMSO-d 6 ; $500 \mathrm{MHz}$ ) $\delta$, ppm: 2.09 (s, 3H, $\mathrm{CH}_{3}$ ), 6.01 (s, 1H, $\left.\mathrm{CH}_{2}=\right), 6.43\left(\mathrm{~s}, 1 \mathrm{H}, \mathrm{CH}_{2}=\right), 7.64(\mathrm{~m}, 3 \mathrm{H}, \mathrm{ArH}), 7.75$ (m, 2H, ArH), $7.95(\mathrm{~d}, 1 \mathrm{H}, \mathrm{ArH}), 8.07(\mathrm{~d}, 2 \mathrm{H}, \mathrm{ArH}), 9.04(\mathrm{~d}$, $1 \mathrm{H}, \mathrm{ArH}), 9.31(\mathrm{~d}, 1 \mathrm{H}, \mathrm{ArH})$.

2-methyl-5-[(E)-p-phenyldiazenyl]quinolin-8-yl 2-methylprop-2-enoate (m2a). Orange crystals, yield $84 \%$. $\mathrm{Mp}=110-111^{\circ} \mathrm{C} .{ }^{1} \mathrm{H}$ NMR (DMSO-d 6 ; $400 \mathrm{MHz}$ ) $\delta$, ppm: $2.10\left(\mathrm{~s}, 3 \mathrm{H}, \mathrm{CH}_{3}\right), 2.67\left(\mathrm{~s}, 3 \mathrm{H}, \mathrm{CH}_{3}\right), 5.99\left(\mathrm{~s}, 1 \mathrm{H}, \mathrm{CH}_{2}=\right)$, $6.41\left(\mathrm{~s}, 1 \mathrm{H}, \mathrm{CH}_{2}=\right), 7.63(\mathrm{~m}, 5 \mathrm{H}, \mathrm{ArH}), 7.86(\mathrm{~d}, 1 \mathrm{H}, \mathrm{ArH})$, 8.05 (d, 2H, ArH), 9.17 (d, 1H, ArH).

5-[(E)-(4-methoxyphenyl)diazenyl]-2-methylquinolin-8-yl 2-methylprop-2-enoate (m2b). Bright orange powder, yield $54 \% . \mathrm{Mp}=123-125^{\circ} \mathrm{C} .{ }^{1} \mathrm{H}$ NMR (DMSO-d $\left.{ }_{6} ; 400 \mathrm{MHz}\right) \delta$, ppm: $2.10\left(\mathrm{~s}, 3 \mathrm{H}, \mathrm{CH}_{3}\right), 2.66\left(\mathrm{~s}, 3 \mathrm{H}, \mathrm{CH}_{3}\right), 3.89(\mathrm{~s}, 3 \mathrm{H}$, $\left.\mathrm{OCH}_{3}\right), 5.98\left(\mathrm{~s}, 1 \mathrm{H}, \mathrm{CH}_{2}=\right), 6.40\left(\mathrm{~s}, 1 \mathrm{H}, \mathrm{CH}_{2}=\right), 7.16(\mathrm{~d}$, 
2H, ArH), 7.62 (m, 2H, ArH), 7.81 (d, 1H, ArH), 8.05 (d, $2 \mathrm{H}, \mathrm{ArH}), 9.15$ (d, 1H, ArH).

\section{Polymerization}

Polymers qA-H-H, qA-H- $\mathrm{CH}_{3}$, and qA-OCH$-\mathrm{CH}_{3}$ were synthesized by free-radical polymerization. The polymerization was carried out in $10 \mathrm{wt} \% \mathrm{~N}, \mathrm{~N}^{\prime}$-dimethylformamide solution of corresponding monomers $\mathrm{m} 1 \mathrm{a}, \mathrm{m} 2 \mathrm{a}, \mathrm{m} 2 \mathrm{~b}$ and methyl methacrylate (MMA) with monomers initial mole ratios 1:3. The polymerization was conducted using AIBN as a free radical initiator $\left(1 \mathrm{wt} \%\right.$ of monomer) at $80^{\circ} \mathrm{C} 48 \mathrm{~h}$ in argon atmosphere in the same way as reported (Guichaoua et al. 2019; Trefon-Radziejewska et al. 2019). The copolymerization ratios were calculated on the basis of the integrated peak areas of ${ }^{1} \mathrm{H}$ NMR spectra in DMSO- $\mathrm{d}_{6}$.

Figure 1 shows the synthetic route of studied methacrylate copolymers containing quinoline azo-dyes in side chain. The copolymers are composed of methyl methacrylate unit and methacrylic azoesters, in which chromophore is covalently bonded as side chain.

\section{Sample preparation}

Thin films of azo-quinoline containing copolymers were deposited with spin-coating method. Previously, the glass substrates used were carefully cleaned in a commercial surfactant using ultrasonication and washed several times in deionized water. The cleaning procedure was ended by baking in a $200{ }^{\circ} \mathrm{C}$ oven for $60 \mathrm{~min}$. Droplets of $100 \mathrm{~g} / \mathrm{L}$ solution of polymers in 1,2-dichloroethane were casted onto immobile substrates and then spinned. Thin films formed on silicon substrates were used for ellipsometric measurements, while thin films deposited on BK7 glass slides were used for AFM, transmission and isomerization studies.
Silicon substrates (surface roughness $<5 \AA$ ) were bought from Łukasiewicz Research Network-Institute of Electronic Materials Technology (Poland) and used as they were without any pretreatment or cleaning. Whereas, the glass slides were sequentially cleaned with detergent, then batched in hot DMF and rinsed with acetone.

Samples for transmission and ellipsometric measurements, as well as for isomerization studies, were deposited using Compact Coater Cy-Ez4 (Zhengzhou CY Scientific Instrument Co., Ltd.). The speed of spin coating was $2000 \mathrm{rpm}$, acceleration was $1000 \mathrm{rpm} / \mathrm{s}$ and time of the whole procedure was $60 \mathrm{~s}$. Thin films for AFM studies were prepared with Microprocessor-Controlled Spin Coater SCC200 (Novocontrol Technologies GmbH \& Co. KG, Germany). Deposition procedure was divided into two parts. First, after dropping the polymer solution onto the substrate, it was initially accelerated (with acceleration $480 \mathrm{rpm} / \mathrm{s}$ ) until its speed reached $2400 \mathrm{rpm}$. Then, after $30 \mathrm{~s}$, it was accelerated again (with acceleration $240 \mathrm{rpm} / \mathrm{s}$ ) to the speed of $3600 \mathrm{rpm}$, and after $30 \mathrm{~s}$ it was stopped.

\section{Material characterization}

${ }^{1} \mathrm{H}$ NMR (400 MHz) spectra were recorded on a Mercury (Varian) spectrometer in DMSO- $\mathrm{d}_{6}$ at $21^{\circ} \mathrm{C}$. Chemical shifts are given in $\mathrm{ppm}$ from tetramethylsilane.

The topology of all studied side-chain azo-polymer thin films on glass substrates was examined with Atomic Force Microscope (AFM). To obtain the images, MultiMode NanoScope IIIa (Veeco Metrology Inc., USA) device was used. The device was operating in tapping mode in air at room temperature and the standard silicon tips (Veeco) were used. The imaging scan size was $5 \mu \mathrm{m} \times 5 \mu \mathrm{m}$. Measurements were performed on as prepared samples as well as after 20 min of illumination under $365 \mathrm{~nm}$ UVA light with

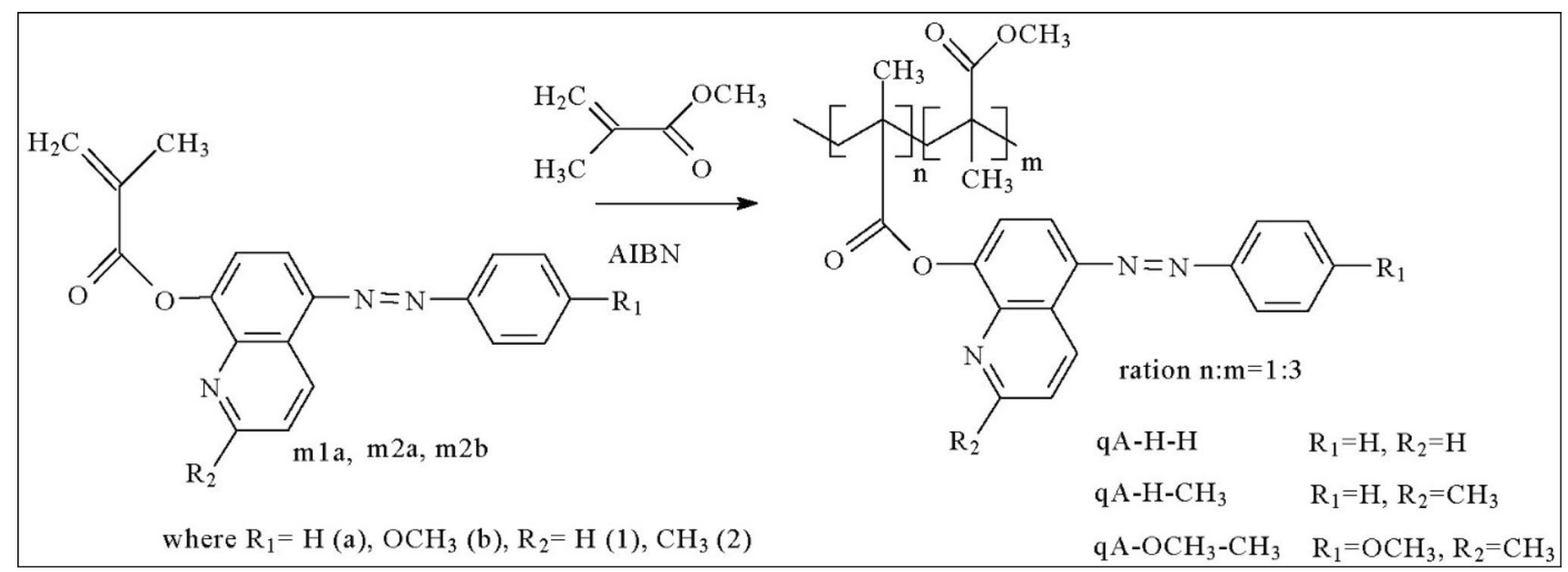

Fig. 1 Polymerization of azo-quinoline methacrylate monomers 
irradiance of $2.15 \mathrm{~W} / \mathrm{m}^{2}$ (F6T5BLB $6 \mathrm{~W}$ lamp from Roger Electronic Products Co., Ltd.). The roughness parameters $R_{a}$ $\left(R_{a}=\frac{1}{N} \sum_{i=1}^{N}\left|y_{i}\right|\right.$-arithmetical mean deviation) and $R_{q}$ $\left(R_{q}=\sqrt{\frac{1}{N} \sum_{i=1}^{N} y_{i}^{2}}\right.$-root mean squared deviation) were determined using NanoScope Analysis software (version 1.40) for the whole scan area.

Transmittance spectra of side-chain azo-quinoline polymer thin films on glass substrates were measured with Cary 5000 (Agilent) spectrophotometer in the spectral range 2.0-4.2 eV. The transmittance spectra of polymeric thin films were recorded in the relation to the identical clear substrate after pretreatment procedure.

Extinction coefficient $(\kappa)$ and refractive index $(n)$ as well as thickness of the azo-quinoline containing copolymers thin films on silicon substrate were determined using spectroscopic ellipsometry (V-VASE ellipsometer from J.A. Woollam Co., Inc.) in the range of $2.0 \mathrm{eV}-4.2 \mathrm{eV}$. Ellipsometric azimuths $(\Psi, \Delta)$ were measured for three angles of incidence $\left(65^{\circ}, 70^{\circ}, 75^{\circ}\right)$. The optical constants and thickness of studied samples were determined using the following optical model of the sample: silicon/silicon oxide/polymer layer. These optical constants were parameterized using Gaussshape dispersion relation in the absorption regime (Skowronski et al. 2015; Fujiwara 2007; Woollam 2010).

Photoisomerization studies were performed on thin films of side-chain azo-quinoline polymers deposited on glass substrates. Samples were irradiated under RR-818 UV lamp (Royal Rouge) ( $4 \times 9$ W $365 \mathrm{~nm}$ bulbs). UV-VIS absorption spectra were recorded using Cary 5000 (Agilent) in the spectral range 2.0-4.2 eV, for different times of irradiation and accumulated time of irradiation is given.

Photoisomerization rates $p$ were obtained from the slopes of the linear functions fitted to photoisomerization kinetic data according to the following equation (Airinei et al. 2011):

$\ln \left(\frac{A(0)-A_{P S S}}{A(t)-A_{P S S}}\right)=p t$,

where $A(0), A_{P S S}$ and $A(t)$ are absorbance values before irradiation, at the photo-stationary state and at accumulated irradiation time $t$ at the wavelength of absorbance maximum before irradiation. Trans-cis photoisomerization rate is given by the relation (Airinei et al. 2011):

$p=I_{0}\left(\varepsilon_{t} \phi_{t c}+\varepsilon_{c} \phi_{c t}\right) \ln 10+k$,

where $\varepsilon_{t}$ and $\varepsilon_{c}$ are molar absorption coefficients of the trans and cis isomers at irradiation wavelength, $\phi_{t c}$ and $\phi_{c t}$ represent photoisomerization quantum yields of trans-cis and cis-trans photoisomerization reaction, $I_{0}$ is the intensity of irradiation light and $k$ represents the thermal cis-trans isomerization rate.

Degrees of photoisomerization $R$ were evaluated from the relation (Airinei et al. 2011):

$R[\%]=\frac{A(0)-A_{P S S}}{A(0)} \cdot 100 \%$.

Geometry of the chromophores was optimized with Density Functional Theory (DFT) calculations. Calculations were performed for isolated molecules in vacuum. Computations were performed using BP86 exchange-correlation functional and DZP basis set. The magnitudes of molecule's dipole moments were determined and they are listed in Table 1.

\section{Results and discussion}

\section{AFM studies}

Table 2 presents the AFM images for the studied samples. To characterize the surface quality of side-chain azoquinoline polymer thin films, the roughness parameters $\left(R_{a}\right.$ and $R_{q}$ ) were calculated. They are also summarized in Table 2. We found that qA-H-CH ${ }_{3}$ and $\mathrm{qA}-\mathrm{OCH}_{3}-$ $\mathrm{CH}_{3}$ samples have very smooth surfaces with roughness parameters values varying from $0.23 \mathrm{~nm}$ to $0.25 \mathrm{~nm}$ for $R_{a}$ and from 0.31 to $0.41 \mathrm{~nm}$ for $R_{q}$ before their irradiation. Whereas, the surface of the reference sample (i.e. qA-H-H) is not so smooth $\left(R_{a}=1.36 \mathrm{~nm}\right.$ and $\left.R_{q}=1.76 \mathrm{~nm}\right)$. Thus, adding the methyl substituent on the 2 nd position of the quinoline moiety (qA-H-CH $3, \mathrm{qA}-\mathrm{OCH}_{3}-\mathrm{CH}_{3}$ ) makes the surface of the samples smoother compared to qA-H-H. The roughness parameters changed about 5 times due to geometric changes in side chain of polymers before their irradiation. It may indicate a better adjustment of macromolecules in these two samples due to interactions and lower stresses compared to qA-H-H sample. In all these systems nitrogen and oxygen atoms were able to interact with hydrogen atoms, however, these interactions could be difficult owing to the stiffness of the substituents containing aromatic rings and azo group. Replacing hydrogen atom with methyl group in $\mathrm{R}_{2}$ position and methoxy group in $R_{1}$ position led to decrease in the surface roughness as these groups were bigger and also they could rotate contributing to the occupation of energetically privileged

Table 1 Magnitudes of phenylazo-quinoline chromophore's dipole moments

\begin{tabular}{llll}
\hline$R_{1}$ & $\mathrm{H}$ & $\mathrm{H}$ & $\mathrm{OCH}_{3}$ \\
$R_{2}$ & $\mathrm{H}$ & $\mathrm{CH}_{3}$ & $\mathrm{CH}_{3}$ \\
$\begin{array}{c}\text { Dipole } \\
\text { moment }\end{array}$ & 1.7 & 2.4 & 4.2 \\
[Debye] & & & \\
\hline
\end{tabular}


Table 2 Surface topography of the studied side-chain azo-quinoline polymers thin films obtained from AFM and $R_{a}$ and $R_{q}$ values of azo-quinoline thin films $\left(\mathrm{qA}-\mathrm{R}_{1}-\mathrm{R}_{2}\right)$ before and after irradiation

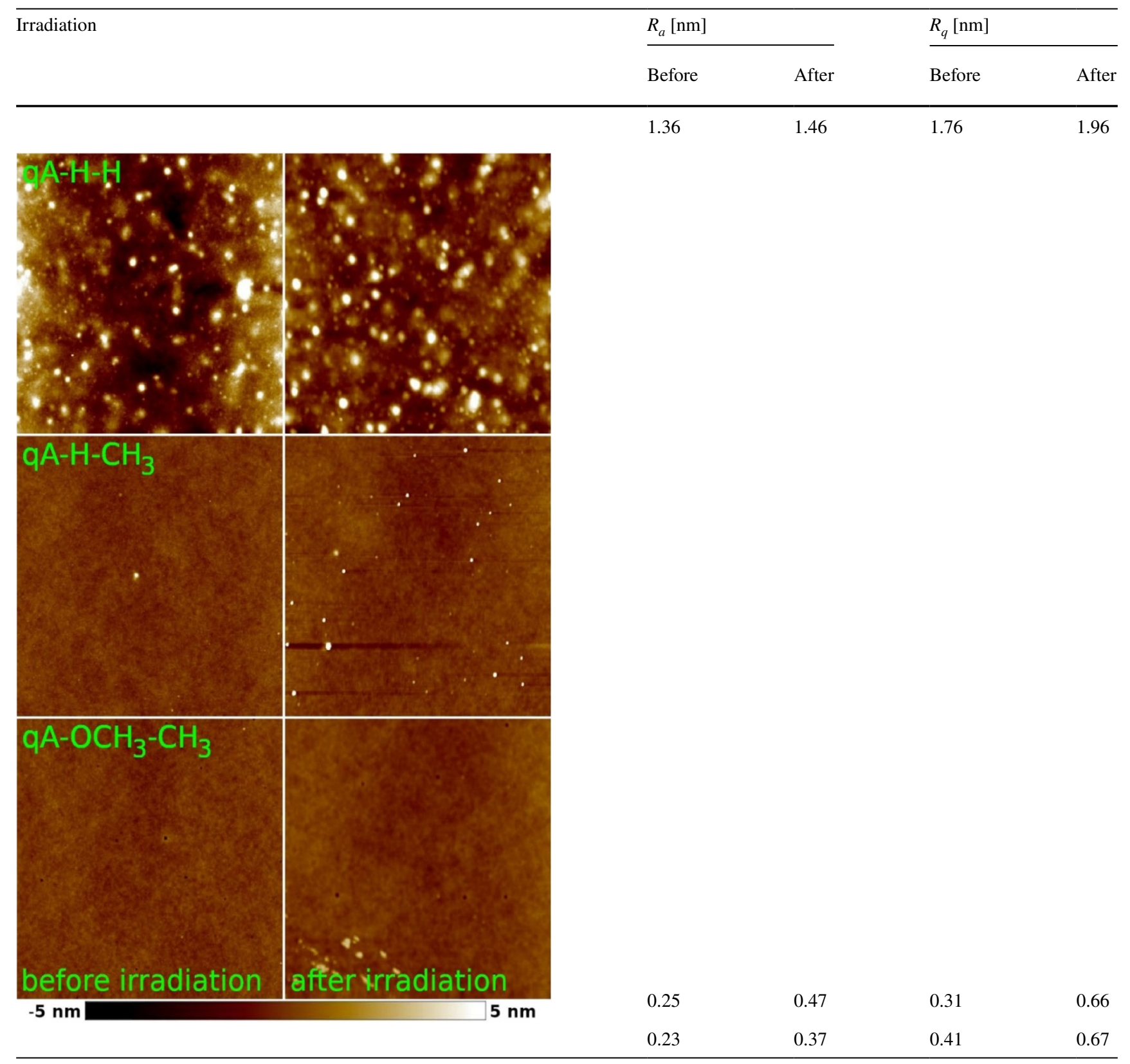

positions by the macromolecules. Although, qA-H-H formed more compact structure, which caused stresses and consequently the increase in its surface roughness.

To check the influence of irradiation on surface quality of azo-quinoline thin films, they were irradiated with UVA light for $20 \mathrm{~min}$ and AFM images were taken again. We found that $R_{a}$ and $R_{q}$ for qA-H-CH 3 and $\mathrm{qA}-\mathrm{OCH}_{3}-$ $\mathrm{CH}_{3}$ thin films changed 1.5-2 times after their irradiation and they changed about 1.1 times for $\mathrm{qA}-\mathrm{H}-\mathrm{H}$. It can also be seen that the roughness parameters for $\mathrm{qA}-\mathrm{H}-\mathrm{CH}_{3}$ and qA-OCH$-\mathrm{CH}_{3}$ changed 3-4 times after their irradiation compared to qA-H-H.

\section{UV-VIS and ellipsometric measurements}

Transmittance spectra of side-chain azo-quinoline polymer thin films on glass substrate are shown in Fig. 2. Whereas, Fig. 3 presents the extinction coefficient $(\kappa)$ of the studied 


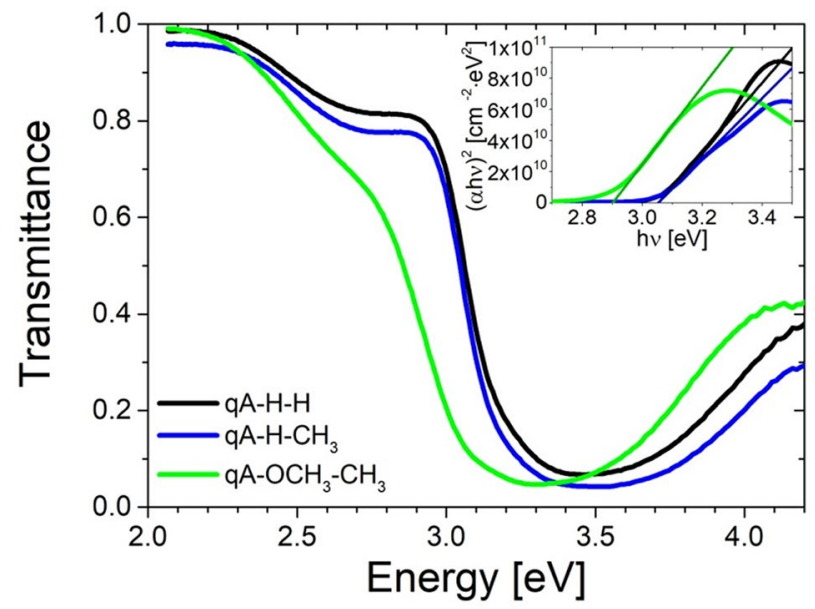

Fig. 2 Transmittance spectra of side-chain quinoline azo-dye polymers. Inset: Tauc plots

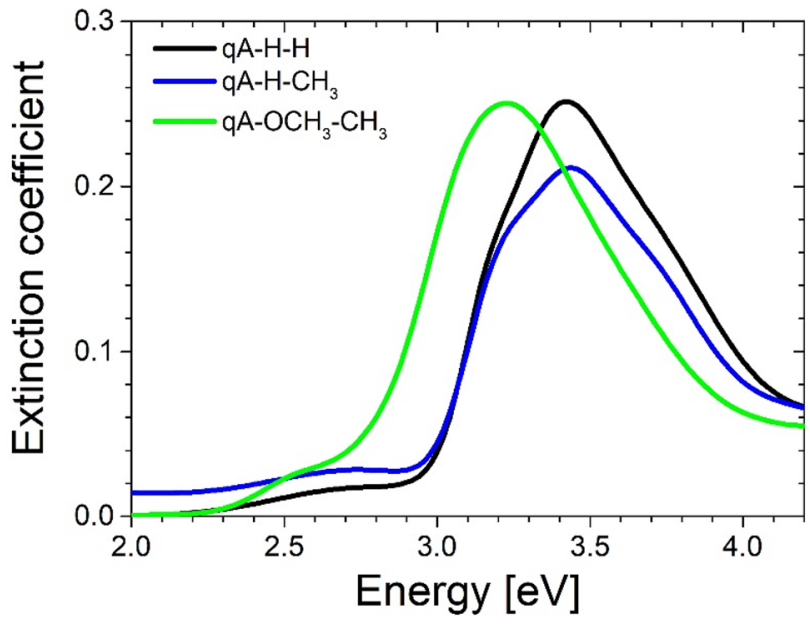

Fig. 3 Extinction coefficient spectra of side-chain azo-quinoline polymers

materials obtained from spectroscopic ellipsometry (SE) measurements. It should be mentioned that the shape of extinction coefficient spectra was parameterized using Gaussian oscillators.

Two bands are shown on both spectra (see Figs. 2 and 3). The $\pi-\pi^{*}$ electronic transition results in a strong absorption band of the polymers in the range from about $3.0 \mathrm{eV}$ to $4.2 \mathrm{eV}$ and the $\mathrm{n}-\pi^{*}$ transition results in weak absorption band in the range from $2.2 \mathrm{eV}$ to about $3.0 \mathrm{eV}$. The $\pi-\pi^{*}$ transition band is broad due to intramolecular charge transfer (ITC) character of these transitions. For all of the studied materials the $\pi-\pi^{*}$ absorption band overlaps relatively poorly with the $\mathrm{n}-\pi^{*}$ band thus they may belong to azobenzenes type molecules according to the Rau classification (Sekkat and Knoll 2002). Interband transitions energy
Table 3 Optical energy band gap $\left(E_{g}\right)$ values and interband transitions energy values for side-chain azo-quinoline polymers, the thickness of the samples $(\mathrm{L})$

\begin{tabular}{llll}
\hline & $\begin{array}{l}\text { qA-H-H (Chomicki } \\
\text { et al. 2020) }\end{array}$ & qA-H-CH & qA-OCH \\
& & $-\mathrm{CH}_{3}$ \\
\hline $\mathrm{L}[\mathrm{nm}]$ & $485 \pm 1$ & $537 \pm 3$ & $572 \pm 2$ \\
$E_{g}[\mathrm{eV}]$ & $3.05 \pm 0.05$ & $3.05 \pm 0.05$ & $2.90 \pm 0.05$ \\
$\mathrm{E}_{1}[\mathrm{eV}]$ & $2.74 \pm 0.02$ & $2.78 \pm 0.04$ & $2.52 \pm 0.03$ \\
$\mathrm{E}_{2}[\mathrm{eV}]$ & $3.15 \pm 0.01$ & $3.18 \pm 0.03$ & $3.04 \pm 0.07$ \\
$\mathrm{E}_{3}[\mathrm{eV}]$ & $3.62 \pm 0.03$ & $3.63 \pm 0.18$ & $3.18 \pm 0.10$ \\
$\mathrm{E}_{4}[\mathrm{eV}]$ & $4.27 \pm 0.03$ & $4.18 \pm 0.20$ & $3.35 \pm 0.04$ \\
$\mathrm{E}_{5}[\mathrm{eV}]$ & - & $4.54 \pm 0.04$ & $4.13 \pm 0.05$ \\
$\mathrm{E}_{6}[\mathrm{eV}]$ & - & $5.76 \pm 0.11$ & $5.84 \pm 0.07$ \\
\hline
\end{tabular}

values determined with spectroscopic ellipsometry are summarized in Table 3.

As can be seen in Table 3 as well as Figs. 2 and 3, the $\mathrm{n}-\pi^{*}$ absorption bands for all samples are described with one oscillator. For the neutral/reference sample (qA-H-H), the transition energy for this oscillator is located at $2.74 \mathrm{eV}$. Adding the methyl substituent at $\mathrm{R}_{2}$ position (qA-H-CH sample) shifts its energy to $2.78 \mathrm{eV}$, while simultaneous addition of methyl group at $\mathrm{R}_{2}$ and methoxy group at $\mathrm{R}_{1}$ site (qA-OCH $-\mathrm{CH}_{3}$ sample) shift its energy to $2.52 \mathrm{eV}$. However, we found that the $\pi-\pi^{*}$ absorption band of the studied materials cannot be described using single gaussian oscillator. For the qA-H-H sample, this band was described with three gaussian oscillators with the energies $3.15 \mathrm{eV}$, $3.62 \mathrm{eV}$ and $4.27 \mathrm{eV}$. The maximum of this absorption band is located at about $3.4 \mathrm{eV}$. We found that the presence of a hydrogen atom in $\mathrm{R}_{1}$ position and a methyl group in $\mathrm{R}_{2}$ position (qA-H-CH ${ }_{3}$ ) causes the slight hypsochromic shift of the maximum $\pi-\pi^{*}$ absorption band (to $3.5 \mathrm{eV}$ ). Whereas, the addition of the electron donating substituents, such as methoxy group and methyl group at $\mathrm{R}_{1}$ and $\mathrm{R}_{2}$ sites (qA$\mathrm{OCH}_{3}-\mathrm{CH}_{3}$ ), respectively, results in bathochromic shift of the maximum $\pi-\pi^{*}$ band to about $3.3 \mathrm{eV}$. From Table 3 , one can see that the $\pi-\pi^{*}$ absorption bands of the qA-H$\mathrm{CH}_{3}$ and $\mathrm{qA}-\mathrm{OCH}_{3}-\mathrm{CH}_{3}$ samples were described with five gaussian oscillators. For qA-H- $\mathrm{CH}_{3}$ the energies of the oscillators were shifted to higher energies $(3.18 \mathrm{eV}, 3.63 \mathrm{eV}$ and $4.54 \mathrm{eV}$ ) with additional two new oscillators (with energies $4.18 \mathrm{eV}$ and $5.79 \mathrm{eV}$ ). For qA- $\mathrm{OCH}_{3}-\mathrm{CH}_{3}$ sample the energies of the three oscillators shifted toward lower energies ( $3.04 \mathrm{eV}, 3.35 \mathrm{eV}$, and $4.13 \mathrm{eV}$ ) and two additional oscillators appeared (at $3.18 \mathrm{eV}$ and $5.84 \mathrm{eV}$ ).

It should be noted that the values of the optical energy band gap $\left(E_{g}\right)$ were calculated using Tauc method (see Table 3). The obtained Tauc plots with extrapolation of the linear part of $(\alpha h \nu)^{2}$ relation are shown in the inset of Fig. 2. From Fig. 2 and Table 3, it can be seen that the energy band gap values for qA-H-H and qA-H-CH 3 are similar. Although 


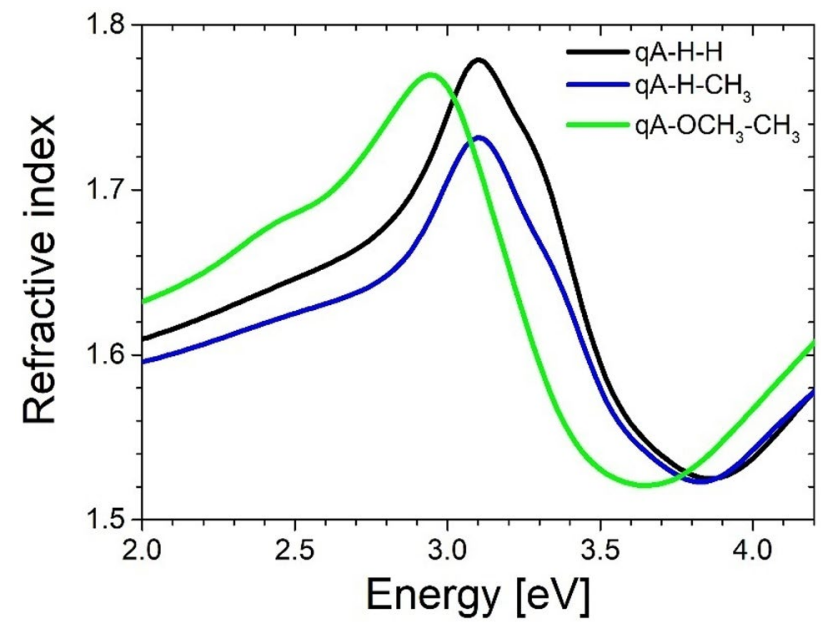

Fig. 4 A dependence of refractive index on energy of the studied side-chain azo-quinoline-containing polymers

the substitution of methoxy group at $\mathrm{R}_{1}$ site and methyl group at $\mathrm{R}_{2}$ position (qA-OCH$-\mathrm{CH}_{3}$ ) reduces the value of the band gap.

Figure 4 shows the refractive index $(n)$ of the studied sidechain azo-quinoline polymers. In the range of $2.0-3.0 \mathrm{eV}$, refractive index shows the normal dispersion. Whereas, the anomalous dispersion is visible from about $3.0-4.2 \mathrm{eV}$. The position of the maximum refractive index (the transition point from anomalous to normal dispersion) shifts to lower energies after adding the methoxy group and the methyl group at $\mathrm{R}_{1}$ and $\mathrm{R}_{2}$ sites $\left(\mathrm{qA}-\mathrm{OCH}_{3}-\mathrm{CH}_{3}\right)$. The same behavior was observed for the value of the optical energy band gap. In the nonabsorbing range (for wavelengths below $3.0 \mathrm{eV}$ ) the value of refractive index decreases in the following order $n_{\text {qA-OCH3-CH3 }}>n_{\text {qA-H-H }}>n_{\text {qA-H-CH3. }}$. Substitution of the methoxy group into the phenyl ring and the methyl group into quinoline moiety (qA-OCH$-\mathrm{CH}_{3}$ ) causes an increase of the refractive index value as compared to reference material (qA-H-H). Whereas, the absent of the methoxy group (qA$\mathrm{H}-\mathrm{CH}_{3}$ ) reduces the value of refractive index in confrontation with qA-H-H.

\section{Photoisomerization studies}

Figure 5 shows changes in the absorption spectra of all studied side-chain azo-quinoline polymers during irradiation with $365 \mathrm{~nm}$ UVA light. Irradiation of the samples causes reduction of intensity of the $\pi-\pi^{*}$ absorption band with its simultaneous hypsochromic shift, while, at the same time, the intensity of the $n-\pi^{*}$ absorption band increases. Isosbestic points visible in the spectra indicate that the isomerization was the only process occurring during sample irradiation with only two species (trans and cis) involved. It
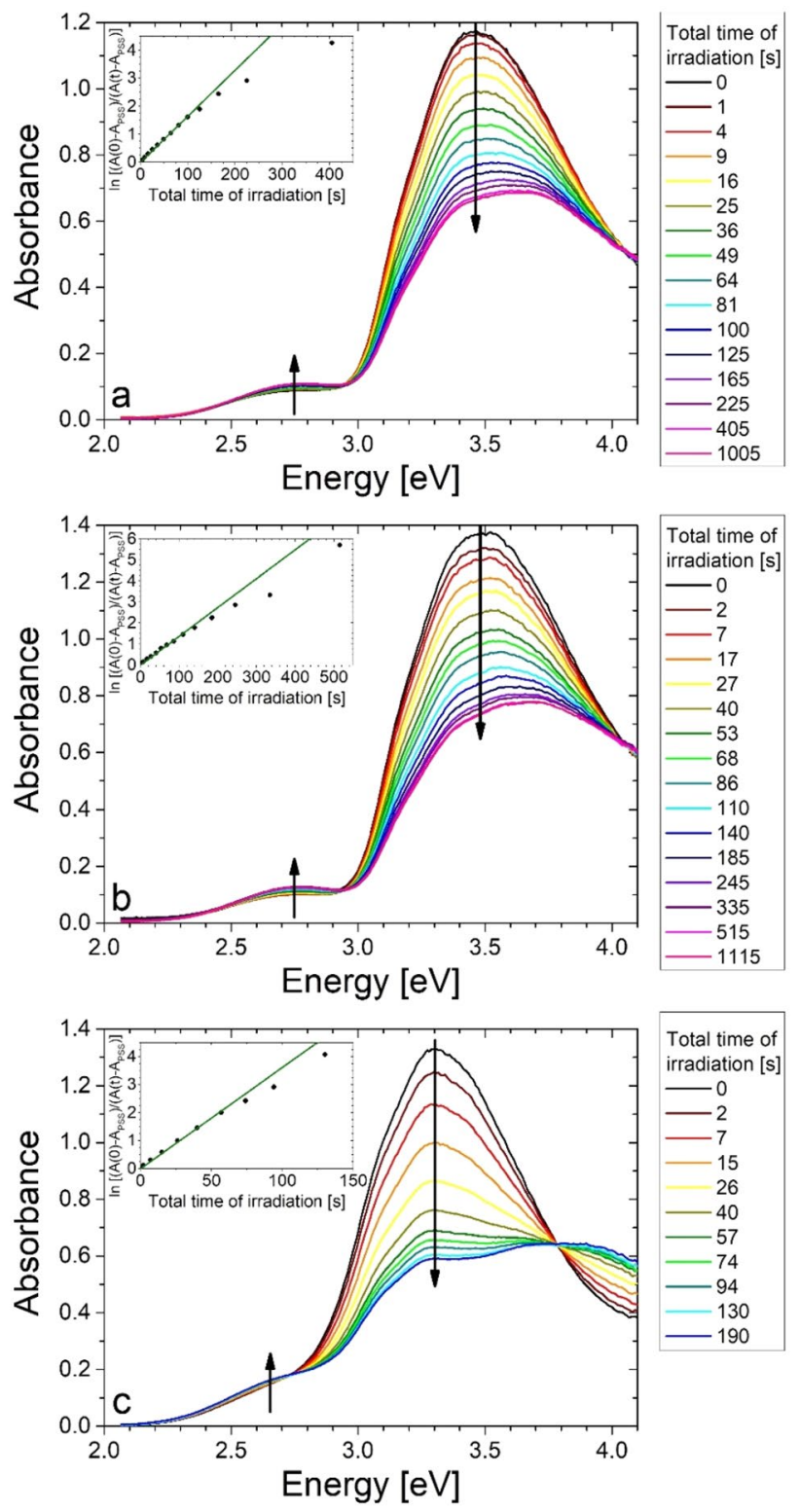

Fig. 5 Changes in absorption spectrum due to photoisomerization for the studied side-chain azo-quinoline polymer samples: a qA-H-H, b qA-H- $\mathrm{CH}_{3}$, c qA-OCH${ }_{3}-\mathrm{CH}_{3}$; insets: $\ln \left(\frac{A(0)-A_{P S S}}{A(t)-A_{P S S}}\right)$ dependence on total time of irradiation (experimental data and linear function fit)

Table 4 Degrees of photoisomerization, isomerization rates, and positions of isosbestic points for side-chain quinoline azo-dye polymer thin films

\begin{tabular}{llll}
\hline Parameters & $\mathrm{qA}-\mathrm{H}-\mathrm{H}$ & $\mathrm{qA}-\mathrm{H}-\mathrm{CH}_{3}$ & $\mathrm{qA}-\mathrm{OCH}_{3}-\mathrm{CH}_{3}$ \\
\hline $\begin{array}{l}\text { Degree of photoisomeriza- } \\
\text { tion }\end{array}$ & 43.4 & 45.4 & 55.6 \\
$R[\%]$ & & & \\
$\begin{array}{l}\text { Isomerization rate } \\
p\left[10^{-3} \cdot \mathrm{s}^{-1}\right]\end{array}$ & $16.4 \pm 0.2$ & $13.7 \pm 0.4$ & $36.1 \pm 0.7$ \\
Isosbestic points & 4.05 & 4.05 & 3.78 \\
{$[\mathrm{eV}]$} & 2.95 & 2.95 & 2.74 \\
\hline
\end{tabular}


should be noted that the positions of the isosbestic points are redshifted following substitution of the methoxy group at $R_{1}$ and methyl group at $R_{2}$.

Degrees of photoisomerization are given in Table 4. The reference sample and compound with the hydrogen atom in $\mathrm{R}_{1}$ and methyl group in $\mathrm{R}_{2}$ achieved a degree of photoisomerization of about $44 \%$ and $45 \%$, respectively. While, the adding the methoxy group in $\mathrm{R}_{1}$ and methyl group in $\mathrm{R}_{2}$ (qA-OCH $-\mathrm{CH}_{3}$ ) increases of degree of photoisomerization above $55 \%$.

The values of trans-cis isomerization rates were obtained by fitting the linear function to the $\ln \left(\frac{A(0)-A_{P S S}}{A(t)-A_{P S S}}\right)$ versus accumulated irradiation time plots shown in the insets of Fig. 5 and are listed in Table 4. Substitution of the hydrogen atom in $\mathrm{R}_{1}$ and the methyl group in $\mathrm{R}_{2}\left(\mathrm{qA}-\mathrm{H}-\mathrm{CH}_{3}\right)$ reduces the isomerization rate compared to neutral sample (qA-H-H). Whereas, the addition of the methoxy group in $\mathrm{R}_{1}$ and methyl group in $\mathrm{R}_{2}\left(\mathrm{qA}-\mathrm{OCH}_{3}-\mathrm{CH}_{3}\right)$ causes the increase of three times the rate of isomerization as compared to qA-H-H and $\mathrm{qA}-\mathrm{H}-\mathrm{CH}_{3}$.

\section{Conclusion}

Side-chain azo-quinoline methacrylic polymers were synthetized and characterized. AFM studies showed that the surface of examined thin films had the smooth surface and their irradiation with $365 \mathrm{~nm}$ UVA light had no influence on their quality.

Optical properties of the polymers were studied with spectroscopic ellipsometry combined with transmittance measurements. The studies revealed that the replacement of the hydrogen atom at 2 nd position of the quinoline moiety with methyl group cause a slightly hypsochromic shift of the absorption band as compared to reference sample. Whereas, the bathochromic shift is observed when the methoxy and methyl groups are in $R_{1}$ and $R_{2}$ positions, respectively. A similar red shift is seen in the case of refractive index. It can also be seen that adding the methoxy group at $\mathrm{R}_{1}$ and methyl group at $\mathrm{R}_{2}$ additionally increases the value of $n$. Although the hydrogen atom in $\mathrm{R}_{1}$ position and a methyl group in $\mathrm{R}_{2}$ position (qA-H- $\mathrm{CH}_{3}$ ) decreases the value of refractive index with respect to qA-H-H. On the other hand, the position of refractive index maximum did not change after the substitution of the methyl group on the quinoline moiety compared to the reference material. Summarizing, in nonabsorbing region the refractive index values increase in the following order $n_{\mathbf{q A}-\mathbf{H}-\mathbf{C H} 3}<n_{\mathbf{q A}-\mathbf{H}-\mathbf{H}}$ $<n_{\text {qA-OCH3-CH3 }}$.

Absorbance studies on the influence of irradiation of the samples with $365 \mathrm{~nm}$ light revealed that all samples exhibit photoisomerization. However, the sample with the methoxy group attached to phenyl ring and the methyl group into the quinoline moiety (qA-OCH$-\mathrm{CH}_{3}$ ) showed the highest degrees of photoisomerization as well as the highest isomerization rate. Thus, the proper design of side-chain quinoline azo-polymers can increase the isomerization rate and degrees of photoisomerization, which contributes to their wider use in new photonic and optoelectronic devices.

Acknowledgements This work was partly supported under the PROM project-International Scholarship Exchange of $\mathrm{PhD}$ Students and Academic Staff funded by the Polish National Agency for Academic Exchange NAWA. This research was partly supported by National Research Foundation of Ukraine, project 2020.02/0022.

Author contributions Conceptualization, B.D.-Z.; Methodology, D.C.; Formal Analysis, D.C., and J.K.; Investigation, D.C., O.Kh., L.S., and J.K.; Resources, O.Kh., V.S., and O.Kr.; Writing-Original Draft Preparation, D.C.; Writing-Review and Editing, L.S, J.K., O.Kr., and B.D.-Z.; Visualization, D.C.; Supervision, B.D.-Z.; Project Administration, B.D.-Z.; Funding Acquisition, D.C., O.Kr. and B.D.Z. All authors have read and agreed to the published version of the manuscript.

Funding This work was partly supported under the PROM projectInternational Scholarship Exchange of PhD Students and Academic Staff funded by the Polish National Agency for Academic Exchange NAWA. This research was partly supported by National Research Foundation of Ukraine, project 2020.02/0022.

\section{Declarations}

Conflict of interest The authors declare no conflict of interest.

Open Access This article is licensed under a Creative Commons Attribution 4.0 International License, which permits use, sharing, adaptation, distribution and reproduction in any medium or format, as long as you give appropriate credit to the original author(s) and the source, provide a link to the Creative Commons licence, and indicate if changes were made. The images or other third party material in this article are included in the article's Creative Commons licence, unless indicated otherwise in a credit line to the material. If material is not included in the article's Creative Commons licence and your intended use is not permitted by statutory regulation or exceeds the permitted use, you will need to obtain permission directly from the copyright holder. To view a copy of this licence, visit http://creativecommons.org/licenses/by/4.0/.

\section{References}

Airinei A, Fifere N, Homocianu M, Gaina C, Gaina V, Simionescu BC (2011) Optical properties of some new azo photoisomerizable bismaleimide derivatives. Int J Mol Sci 12:6176-6193. https:// doi.org/10.3390/ijms12096176

Arslan Ö, Aydıner B, Yalçın E, Babür B, Seferoğlu N, Seferoğlu Z (2017) 8-Hydroxyquinoline based push-pull azo dye: novel colorimetric chemosensor for anion detection. J Mol Struct 1149:499509. https://doi.org/10.1016/j.molstruc.2017.08.001

Bandara D, Burdette SC (2012) Photoisomerization in different classes of azobenzene. Chem Soc Rev 41:1809-1825. https://doi.org/10. 1039/C1CS15179G

Chomicki D, Kharchenko O, Skowronski L, Kowalonek J, KozaneckaSzmigiel A, Szmigiel D, Smokal V, Krupka O, Derkowska-Zielinska B (2020) Influence of substituents on physico-chemical 
and light-induced properties of methacrylic polymers containing quinoline azo-dyes in side chain. Int J Mol Sci 21:5755. https:// doi.org/10.3390/ijms21165755

Derkowska-Zielinska B, Krupka O, Smokal V, Grabowski A, Naparty M, Skowronski L (2016) Optical properties of disperse dyes doped poly(methyl methacrylate). Mol Cryst Liq Cryst 639(1):87-93. https://doi.org/10.1080/15421406.2016.1254585

Derkowska-Zielinska B, Fedus K, Wang H, Cassagne C, Boudebs G (2017a) Nonlinear optical characterization of Disperse Orange 3. Opt Mater 72:545-548. https://doi.org/10.1016/j.optmat.2017.06.055

Derkowska-Zielinska B, Skowronski L, Biitseva A, Grabowski A, Naparty MK, Smokal V, Kysil A, Krupka O (2017b) Optical characterization of heterocyclic azo dyes containing polymers thin films. Appl Surf Sci 421:361-366. https://doi.org/10.1016/j. apsusc.2016.12.080

Derkowska-Zielinska B, Skowronski L, Sypniewska M, Chomicki D, Smokal V, Kharchenko O, Naparty M, Krupka O (2018) Functionalized polymers with strong push-pull azo chromophores in side chain for optical application. Opt Mater 85:391-398. https:// doi.org/10.1016/j.optmat.2018.09.008

Derkowska-Zielinska B, Matczyszyn K, Samoc MM, Czaplicki R, Kaczmarek-Kedziera A, Smokal V, Biitseva A, Krupka O (2019) All-optical poling and two-photon absorption in heterocyclic azo dyes with different side groups. J Phys Chem C 123:725-734. https://doi.org/10.1021/acs.jpcc.8b10621

El Halabieh RH, Mermut O, Barrett CJ (2004) Using light to control physical properties of polymers and surfaces with azobenzene chromophores. Pure Appl Chem 76:1445-1465. https://doi.org/ 10.1351/pac200476071445

El-Ghamaz NA, El-Mallah HM, El-Sonbati AZ, Diab MA, El-Bindary AA, Barakat AM (2013) Optical properties studies on metalligand bonding of novel quinoline azodyes thin films. Solid State Sci 22:56-64. https://doi.org/10.1016/j.solidstatesciences.2013. 05.005

El-Ghamaz NA, El-Menyawy EM, Diab MA, El-Bindary AA, ElSonbati AZ, Nozha SG (2014) Optical and dielectrical properties of azo quinoline thin films. Solid State Sci 30:44-54. https://doi. org/10.1016/j.solidstatesciences.2014.02.005

El-Ghamaz NA, El-Bindary AA, El-Sonbati AZ, Beshry NM (2015) Geometrical structures, thermal, optical and electrical properties of azo quinoline derivatives. J Mol Liq 211:628-639. https://doi. org/10.1016/j.molliq.2015.07.050

Fujiwara H (2007) Spectroscopic ellipsometry: principles and applications. John Wiley and Sons Ltd, New Jersey

Ghanadzadeh AG, Moghadam M, Zakerhamidi MS, Moradi E (2012) Solvatochromism, tautomerism and dichroism of some azoquinoline dyes in liquids and liquid crystals. Dyes Pigments 92:1320 1330. https://doi.org/10.1016/j.dyepig.2011.09.021

Guichaoua D, Kulyka B, Smokal V, Migalska-Zalas A, Kharchenko O, Krupka O, Kolendo O, Sahraouia B (2019) UV irradiation induce NLO modulation in photochromic styrylquinoline-based polymers: computational and experimental studies. Org Electron 66:175-182. https://doi.org/10.1016/j.orgel.2018.12.022

Ho MS, Natansohn A, Rochon P (1995) Azo polymers for reversible optical storage. 7. The effect of the size of the photochromic groups. Macromolecules 28:6124-6127. https://doi.org/10.1021/ ma00122a020

Kawata S, Kawata Y (2000) Three-dimensional optical data storage using photochromic materials. Chem Rev 100:1777-1788. https:// doi.org/10.1021/cr980073p

Merino E, Ribagorda M (2012) Control over molecular motion using the $c i s$-trans photoisomerization of the azo group. Beilstein J Org Chem 8:1071-1090. https://doi.org/10.3762/bjoc.8.119

Natansohn A, Rochon P (2002) Photoinduced motions in azo-containing polymers. Chem Rev 102:4139-4417. https://doi.org/10.1021/ cr970155y
Sankar R, Vijayalakshmi S, Subramanian S, Rajagopan S, Kaliyappan $\mathrm{T}$ (2007) Synthesis and chelation properties of new polymeric ligand derived from 8-hydroxy-5-azoquinoline hydroxyl benzene. Eur Polym J 43:4639-4646. https://doi.org/10.1016/j.eurpolymj. 2007.08.015

Sarkar R, Mondal P, Rajak KK (2014) Synthesis, structure and spectroscopic properties of $\mathrm{Re}(\mathrm{i})$ complexes incorporating 5-arylazo8-hydroxyquinoline: a density functional theory/time-dependent density functional theory investigation. Dalton Trans 43:28592877. https://doi.org/10.1039/C3DT52630E

Saylam A, Seferoğlu Z, Ertan N (2014) Azo-8-hydroxyquinoline dyes: The synthesis, characterizations and determination of tautomeric properties of some new phenyl- and heteroarylazo-8-hydroxyquinolines. J Mol Liq 195:267-276. https://doi.org/10.1016/j.molliq. 2014.02.027

Sekkat Z, Knoll W (eds) (2002) Photoreactive organic thin films. Academic Press, New York

Skowronski L, Krupka O, Smokal V, Grabowski A, Naparty M, Derkowska-Zielinska B (2015) Optical properties of coumarins containing copolymers. Opt Mater 47:18-23. https://doi.org/10. 1016/j.optmat.2015.06.047

Smokal V, Krupka A, Kharchenko O, Krupka O, Derkowska-Zielinska B, Kolendo A (2018) Synthesis and photophysical properties of new styryquinoline-containing polymers. Mol Cryst Liq Cryst 661:38-44. https://doi.org/10.1080/15421406.2018.1460236

Szala M, Nycz JE, Malecki GJ, Sokolova R, Ramesova S, SwitlickaOlszewska A, Strzelczyk R, Podsiadly R, Machura B (2017) Synthesis of 5-azo-8-hydroxy-2-methylquinoline dyes and relevant spectroscopic, electrochemical and computational studies. Dyes Pigments 142:277-292. https://doi.org/10.1016/j.dyepig.2017. 03.043

Tawa K, Kamada K, Ohta K (2000) Azo-dye-structure dependence of photoinduced anisotropy observed in PMMA films. J Photochem Photobiol A 134:185-191. https://doi.org/10.1016/S10106030(00)00268-9

Tirellia N, Altomare A, Solaro R, Ciardelli F, Follonier S, Bosshard CH, Günter P (2000) Structure-activity relationship of new NLO organic materials based on push-pull azodyes. 4. Side chain polymers. Polymer 41:415-421. https://doi.org/10.1016/S00323861(99)00202-5

Trefon-Radziejewska D, Hamaoui G, Chirtoc M, Horny N, Smokal V, Biitseva A, Krupka O, Derkowska-Zielinska B (2019) Thermophysical properties of methacrylic polymer films with guesthost and side-chain azobenzene. Mater Chem Phys 231:700-707. https://doi.org/10.1016/j.matchemphys.2018.11.054

Wang X (2017) Azo polymers-synthesis functions and applications. Springer, Berlin Heidelberg

Woollam JA Co., Inc (2010) Guide to Using WVASE32®, Wextech Systems Inc., 310 Madison Avenue, Suite 905, New York, NY 10017

Xie S, Natansohn A, Rochon P (1994) Microstructure of copolymers containing disperse red 1 and methyl methacrylate. Macromolecules 27:1885-1890. https://doi.org/10.1021/ma00085a034

Yan Z, Guang S, Xu H, Liu XY (2013) Quinoline-based azo derivative assembly: optical limiting property and enhancement mechanism. Dyes Pigments 99:720-726. https://doi.org/10.1016/j.dyepig. 2013.07.007

Zeyada HM, El-Ghamaz NA, Gaml EA (2013) Effect of substitution group variation on the optical functions of -5-sulfono-7-(4-x phenyl azo)-8-hydroxy quinoline thin films. Curr Appl Phys 13:19601966. https://doi.org/10.1016/j.cap.2013.08.004

Zidan MD, Ajji Z (2011) Optical limiting behavior of disperse red 1 dye doped polymer. Opt Laser Technol 43:934-937. https://doi. org/10.1016/j.optlastec.2010.12.011 